\title{
BMJ Open Evaluating quality in adolescent mental health services: a systematic review
}

\author{
Meaghen Quinlan-Davidson (D) , ${ }^{1}$ Kathryn J Roberts, ${ }^{1}$ Delan Devakumar, ${ }^{1}$ \\ Susan M. Sawyer, ${ }^{2}$ Rafael Cortez, ${ }^{3}$ Ligia Kiss ${ }^{1}$
}

To cite: Quinlan-Davidson M, Roberts KJ, Devakumar D, et al. Evaluating quality in adolescent mental health services: a systematic review. BMJ Open 2021;11:e044929. doi:10.1136/ bmjopen-2020-044929

- Prepublication history and additional online supplemental material for this paper are available online. To view these files, please visit the journal online (http://dx.doi.org/10. 1136/bmjopen-2020-044929).

Received 18 September 2020 Revised 22 March 2021 Accepted 15 April 2021

Check for updates

(C) Author(s) (or their employer(s)) 2021. Re-use permitted under CC BY. Published by BMJ.

${ }^{1}$ Institute for Global Health, University College London,

London, UK

${ }^{2}$ Centre for Adolescent Health, Royal Children's Hospital;

Murdoch Children's Research Institute; and Department of

Paediatrics, The University of

Melbourne, Parkville, Victoria, Australia

${ }^{3}$ Health, Nutrition and

Population, The World Bank,

Washington, District of

Columbia, USA

\section{Correspondence to}

Meaghen Quinlan-Davidson;

meaghen.quinlan-davidson.17@ ucl.ac.uk

\section{ABSTRACT}

Objectives To evaluate the quality of adolescent mental health service provision globally, according to the WHO Global Standards of adolescent mental health literacy, appropriate package of services and provider competencies.

Design and data sources Systematic review of 5 databases, and screening of eligible articles, from 1 January 2008 to 31 December 2020.

Study eligibility criteria We focused on quantitative and mixed-method studies that evaluated adolescent mental health literacy, appropriate package of services and provider competencies in mental health services, and that targeted depression, anxiety and post-traumatic stress disorder among adolescents (10-19 years). This included adolescents exposed to interventions or strategies within mental health services.

Study appraisal and synthesis methods Study quality was assessed using the National Institutes for Health Study Quality Assessment Tools. Data were extracted and grouped based on WHO quality Standards.

Results Of the 20104 studies identified, 20 articles were included. The majority of studies came from high-income countries, with one from a low-income country. Most of the studies did not conceptualise quality. Results found that an online decision aid was evaluated to increase adolescent mental health literacy. Studies that targeted an appropriate package of services evaluated the quality of engagement between the therapist and adolescent, patient-centred communication, mental health service use, linkages to mental health services, health facility culture and intensive community treatment. Provider competencies focused on studies that evaluated confidence in managing and referring adolescents, collaboration between health facility levels, evidence-based practices and technology use. Conclusions and implications There is limited evidence on quality measures in adolescent mental health services (as conforms to the WHO Global Standards), pointing to a global evidence gap for adolescent mental health services. There are several challenges to overcome, including a need to develop consensus on quality and methods to measure quality in mental health settings.

PROSPERO registration number CRD42020161318.

\section{INTRODUCTION}

Globally, a significant burden of disease is due to mental health disorders. ${ }^{1-3}$ Symptoms largely emerge during childhood, adolescence and young adulthood, ${ }^{1-4}$ with
Strengths and limitations of this study

This is the first review to investigate quality measures for adolescent mental health services globally.

- This review highlights a critical gap in evidence on quality in adolescent mental health services.

- This review was limited to mental health services to adolescents in health facilities. It did not review the quality of mental health preventative or health promotion activities that are typically provided in other settings such as communities or schools.

- The review investigated adolescents with depression, anxiety and post-traumatic stress disorder and not those with other mental health conditions.

estimates suggesting that by 24 years of age, $75 \%$ of adult mental health disorders have appeared. ${ }^{56}$ Current global estimates indicate that $14.8 \%$ of young people aged $10-24$ years have a mental health disorder, ${ }^{7}$ with the most common being unipolar depressive disorders, anxiety disorders and self-harm. ${ }^{5}$ Depressive disorders rank as the fourth highest contributor to disability adjusted life years in 10-14 years old $(4.3 \%)$ and the third highest among 15-19 years old $(5.6 \%)$. Meanwhile, depressive and anxiety disorders rank among the top six contributors to years lived with disability for $10-14$ years old $(7.4 \%$ and $5.0 \%$, respectively) and among the top five for 15-19 years old $\left(11.2 \%\right.$ and $5.8 \%$, respectively). ${ }^{3}$ In addition, a meta-analysis found that $16 \%$ of children and adolescents (2-18 years of age) develop post-traumatic stress disorder (PTSD) after exposure to a traumatic event. ${ }^{8}$ Depression, anxiety and PTSD can be influenced by internal and external stressors. ${ }^{9-11}$ These stressors can arise from living in challenging settings, experiencing traumatic events and life transitions, ${ }^{101213}$ and are exacerbated by the COVID-19 pandemic. ${ }^{1415}$ Despite their prevalence, the quality of mental health services, particularly within challenging environments, is limited. ${ }^{9}$

Mental health conditions have short-term and long-term health, education, social and 
Box 1 Health service barriers to quality adolescent mental health services

\section{Health service barriers}

- Limited financial resources.

- Limited literacy on quality in mental healthcare, with limited or lack of quality criteria or measures.

- Lack of routine assessment of quality in services.

- Limited availability of specialised mental healthcare providers or those appropriately trained in mental health to engage and respond to adolescents' mental health needs.

- Healthcare provider stigma, as a behavioural barrier to quality mental healthcare.

- Lack of information, education and engagement from the health system to the community about adolescent mental health services and promotion of adolescent mental health literacy.

- Limited adolescent involvement in decisions about their treatment and care plans that are required for patient-centred care.

- Lack of youth-friendly, or patient-centred, services that ensure privacy, confidentiality (including confidentiality from parents and other service providers), respect, high-quality communication and services that are non-judgemental and free of embarrassment.

- Lack of equitable (geographically and socioeconomically) distribution of mental health services.

- Overburdened primary care systems which make it hard to integrate adolescent mental health services.

- Lack of mental health leadership from policy-makers and decisionmakers at local and national government levels to champion quality in adolescent mental health services.

Sources: Knaak et $\mathrm{al}^{96}$; Saraceno et $\mathrm{al}^{23}$; McPherson ${ }^{107}$; Svirydzenka et al. ${ }^{108}$

economic impacts including early school leaving, social isolation, substance misuse, chronic unemployment and high economic costs for families, communities and health systems. ${ }^{1-4}$ Yet, despite increased attention on adolescent mental health in recent years, adolescents with mental health conditions experience worse quality of care in comparison to other age groups. ${ }^{16}$ Poor-quality healthcare is associated with worse health outcomes, comorbid conditions and a lack of trust in the health system. It also places the adolescent at an increased risk of death due to inadequate healthcare management, treatment and follow-up. ${ }^{16}$

Quality in mental healthcare is an important component of service delivery that contributes to adolescents seeking, receiving and continuing care. The Institute of Medicine and WHO define quality healthcare as the degree to which health services for individuals and populations increase the likelihood of desired health outcomes and are consistent with current professional knowledge' ${ }^{17}$ Adolescents benefit from mental health services that are adolescent-friendly, defined as accessible, acceptable, equitable, appropriate and effective. ${ }^{18} 19$

There are many multifaceted barriers that influence quality in mental healthcare services (box 1).

For adolescents and their families, barriers to quality mental healthcare start with access to these services. The stigma and discrimination associated with mental health disorders, as well as how adolescents, families, communities and health services conceptualise emotional suffering and distress are significant barriers to access and use of quality mental health services. ${ }^{20}$ Even in well-resourced contexts where mental health services are available, social and cultural conceptualisations of mental health influence the uptake and subsequent coverage of adolescent mental health services. ${ }^{20}$ Adolescents are often less-experienced users of mental health services, with inadequate mental health literacy, including literacy about quality of care. They value privacy, confidentiality and patient-centred care, which includes respect, highquality communication, and a therapist who is responsive to their needs. They seek to avoid judgement and embarrassment, and fear that their parents will be informed can limit their uptake of health services. ${ }^{4}$

There have been several global initiatives focusing on quality of healthcare in recent years (table 1). In 2015, the WHO developed Global standards for quality healthcare services for adolescents to support health service delivery and quality improvements for adolescents in primary and referral level facilities. ${ }^{21}$ The aim of these standards was to increase adolescents' use of health services, improve health outcomes, ensure a minimal level of quality, and fulfil their rights to healthcare. ${ }^{21}$ There are eight standards, all of which are important to ensuring quality in healthcare services. This includes adolescents' health literacy, community support, appropriate package of services, provider competencies, facility characteristics, equity and non-discrimination, data and quality improvement, and adolescent participation. ${ }^{21}$ Notwithstanding the relevance of all standards to quality health services, three standards are particularly important for helpseeking behaviour among adolescents. ${ }^{22-24}$

1. Adolescents' health literacy whereby adolescents know about mental health and their own mental health (through the health facility), as well as knowing where health services are located and when to go. ${ }^{21}$

2. An appropriate package of services in which the health facility meets the needs of the adolescent by providing evidence-based information, counselling, correct diagnoses, treatment and care services. ${ }^{21}$

3. Providers' competencies, whereby healthcare providers are competent and provide effective care to adolescents (including respecting, protecting and fulfilling the rights of adolescents). ${ }^{21}$

These standards reflect the possibilities of interactions between adolescents and health services in terms of access, communication and competency of care. ${ }^{16}$ Yet to date, there has been little research evaluating these standards with no systematic review of the evidence. Recent literature has argued that despite mental health conditions having their first onset during adolescence and young adulthood, these conditions often go undetected. ${ }^{5212526}$ Adolescent mental health literacy empowers adolescents to recognise mental health symptoms and conditions, seek services, understand how they can improve their mental health, as well as combat stigma. ${ }^{51}{ }^{25}$ An appropriate 
Table 1 Definitions of quality by organisation and criteria

\begin{tabular}{|c|c|c|}
\hline Organisations & Definition & Criteria \\
\hline $\begin{array}{l}\text { Lancet Global Health } \\
\text { Commission for High Quality } \\
\text { Health Systems }(2018)^{16}\end{array}$ & $\begin{array}{l}\text { Quality health systems ensure } \\
\text { that healthcare is optimised. } \\
\text { This occurs by responding to } \\
\text { population needs, providing } \\
\text { care that maintains or improves } \\
\text { health outcomes, and ensuring } \\
\text { that all individuals feel valued }\end{array}$ & $\begin{array}{l}\text { Quality framework components } \\
\text { Quality impacts: better health, confidence in system and } \\
\text { economic benefit } \\
\text { Processes of care: competent care and systems, positive } \\
\text { user experience } \\
\text { Foundations: population, governance, platforms, workforce, } \\
\text { tools }\end{array}$ \\
\hline
\end{tabular}

package of services is key to overall quality of adolescent mental healthcare; it ensures that adolescents receive 'adolescent-friendly', comprehensive (promotion, prevention, diagnosis and treatment) mental healthcare. Prior evidence has found that health services for adolescents have focused on a limited range of services, such as sexual and reproductive health, with the service not equipped to deliver mental services to adolescents. ${ }^{521}$ At the centre of providing quality adolescent mental healthcare is provider competencies, which includes providers' knowledge, attitudes and skills, as well as the provision of evidence-based care. ${ }^{212728}$ Prior evidence has found that healthcare providers often do not have the technical competence to promote, prevent and manage adolescent mental health cases. ${ }^{4}$

Despite a growing interest and investment in adolescent mental healthcare services, and the quality of such services, evidence on care quality and its effectiveness remain limited. ${ }^{16}$ There is particularly poor information about how quality mental health services for adolescents should be developed and organised, clinicians trained, and health facility interventions implemented to improve adolescents' mental health outcomes and that meet their needs. ${ }^{29-31}$ This gap is particularly relevant for adolescents in adverse family and social circumstances. ${ }^{9} 10$ The objective of this systematic review is to evaluate the quality of adolescent mental health service provision globally, according to the WHO Global Standards of adolescent mental health literacy, provider competencies and an appropriate package of services. ${ }^{21}$ This review focuses on quantitative and mixed-method evaluations of mental health services for 10-to-19 year olds adolescents with suspected or diagnosed cases of depression, anxiety and PTSD.

\section{METHODS}

For this systematic review, we used the WHO Global Standards for quality healthcare services for adolescents, focusing on standards for mental health services. ${ }^{21}$

\section{Selection criteria}

Inclusion criteria were quantitative and mixed-method studies that evaluated or assessed quality measures as defined by the WHO Global Standards (adolescent mental health literacy, provider competencies, and appropriate package of services) applied to existing mental health services targeted to adolescents (10-19 years) for depression, anxiety and PTSD. We used the Lancet Global Health Commission for High Quality Health Systems ${ }^{16}$ conceptual framework to choose three of the WHO quality Standards. Although all dimensions of the conceptual framework are relevant to a high-quality health system, we were most interested in focusing on the population that the health service is serving, the delivery of competent mental healthcare and the systems and processes of providing care. ${ }^{9}$ Depression and anxiety are the most common mental health outcomes in adolescents living in challenging environments. $^{32-37}$ PTSD is also associated with living in challenging environments. There is evidence that exposure to both interpersonal (eg, assault, war terrorism and injury due to violence) and non-interpersonal (eg, accidents, natural disasters, sudden death of a loved one, witnessing or hearing about death or death threats and life-threatening diseases) trauma, characteristics typical of challenging environments, is associated with the development of PTSD. ${ }^{82-38}$ Furthermore, environments in which adolescents are more likely to experience adversities associated with these disorders are often in settings where quality mental healthcare is scarce. ${ }^{9}$

Articles that focused on adolescent mental health literacy, appropriate package of services, and provider competencies 
were identified and classified according to the process and output criteria in the WHO report found in online supplemental material 2. ${ }^{21}$ Articles were included if adolescents had used or were currently using mental health services, or were exposed to interventions or strategies within established mental health services. Mental health services were defined as health services delivered at the primary, secondary, or higher health facility level that offered prevention and treatment for anxiety, depression or PTSD, as well as any community-based initiatives originating from these health service levels. Articles about healthcare providers delivering mental health services to adolescents were also included. No exclusions were made by country. In cases where studies included individuals aged 18-24 years or 0-10 years, inclusion criteria were met as long as 10-19 years old were the primary population of the study, meaning $>50 \%$ of the study population and the median being within the age range of interest.

While mental health services can be delivered through school-based health services, we restricted the search to more generic and specialised healthcare facilities. Transition services for adolescents to adult services were also excluded as we strictly focused on 10-19 years old. Clinical interventions that focused solely on improving health outcomes were also excluded if they did not detail how quality measures were used. Mental health conditions linked to a comorbid physical health condition or learning disability were also excluded, given the more complex ways in which depression and anxiety can present in these groups, and the extent to which PTSD can reflect comorbid physical conditions in particular. We did not include schizophrenia spectrum disorders, bipolar disorders or adolescent precursors of these two severe groups of mental health conditions, as the median age of onset is older than the 10-19 years old age range and these disorders are less common than anxiety, depression and PTSD. We did not include studies that focused on "at-risk mental states", as evidence indicates that current risk identification approaches are limited within mental health services. ${ }^{39}$ Our primary interest was public health services, which led to us excluding private healthcare services. Family therapy was also excluded as we wanted to focus on services that more directly targeted adolescents. ${ }^{4}$ Given the launch of the Mental health Gap Action Programme guidelines by the WHO in $2008^{40}$ which highlights the large treatment gap globally, studies prior to 2008 were excluded. ${ }^{41}$ No language restrictions were applied.

\section{Search strategy}

The Preferred Reporting Items for Systematic Reviews and Meta-Analyses (PRISMA) methodology was used to select the articles (online supplemental material 3 contains the
PRISMA checklist). ${ }^{42}$ Peer-reviewed literature was searched through the following databases: Pubmed, PsycINFO, MEDLINE, EMBASE and LILACS from 1 January 2008 to 31 December 2020. Articles were also found by screening references in selected scientific articles that matched eligibility for inclusion. The search strategy is provided in table 2.

\section{Data collection and extraction}

Titles and abstracts were exported to Endnote ${ }^{43}$ and scanned for relevance by MQ-D. Articles were removed if they did not meet inclusion criteria or were duplicates. The full text of included articles was obtained and studies were classified in relation to: (1) mental health literacy; (2) appropriate package of services or (3) provider competencies. Dual screening was conducted by two authors (MQ-D and KJR) to ensure that they met the inclusion criteria for this review.

\section{Data synthesis and quality assessment}

A narrative synthesis of the included studies was undertaken as the lack of homogeneity precluded a quantitative synthesis of findings. The methodological quality of the studies was assessed using the National Institutes for Health (NIH) Study Quality Assessment Tools. ${ }^{44}$ Studies were assessed for sources of bias (eg, patient selection, performance, attrition and detection), confounding, study power and strength of causality in the association between interventions and outcomes. ${ }^{44}$ Two reviewers (MQ-D and KJR) divided the studies in half $(50 / 50)$ and rated each study independently. They then checked each other's coding for agreement. Disagreements were resolved through discussion with a third reviewer (LK). Based on the ratings of each component, each study received an overall rating of good, fair, poor. Extracted data were entered into a table of study characteristics, including the quality assessment ratings for each study (table 3 and additional information found in online supplemental material 4).

\section{Patient and public involvement}

Patients and the public were not involved.

\section{RESULTS}

\section{Study selection}

Figure 1 shows the results of the search and selection strategy. Of 20104 references identified, 456 full-text articles met inclusion criteria from which a total of 20 articles were included in the study.

Table 2 Search strategy of electronic databases

\begin{tabular}{llll}
\hline Evaluation terms & Quality terms & Population & Setting \\
\hline Evaluation & Quality & Adolescent & Mental health service \\
Assessment & Health literacy & Youth & Primary mental health service \\
& Appropriate package of services & Teen & Mental health counselling \\
& Provider competencies & Young people & General practitioner service \\
\hline
\end{tabular}




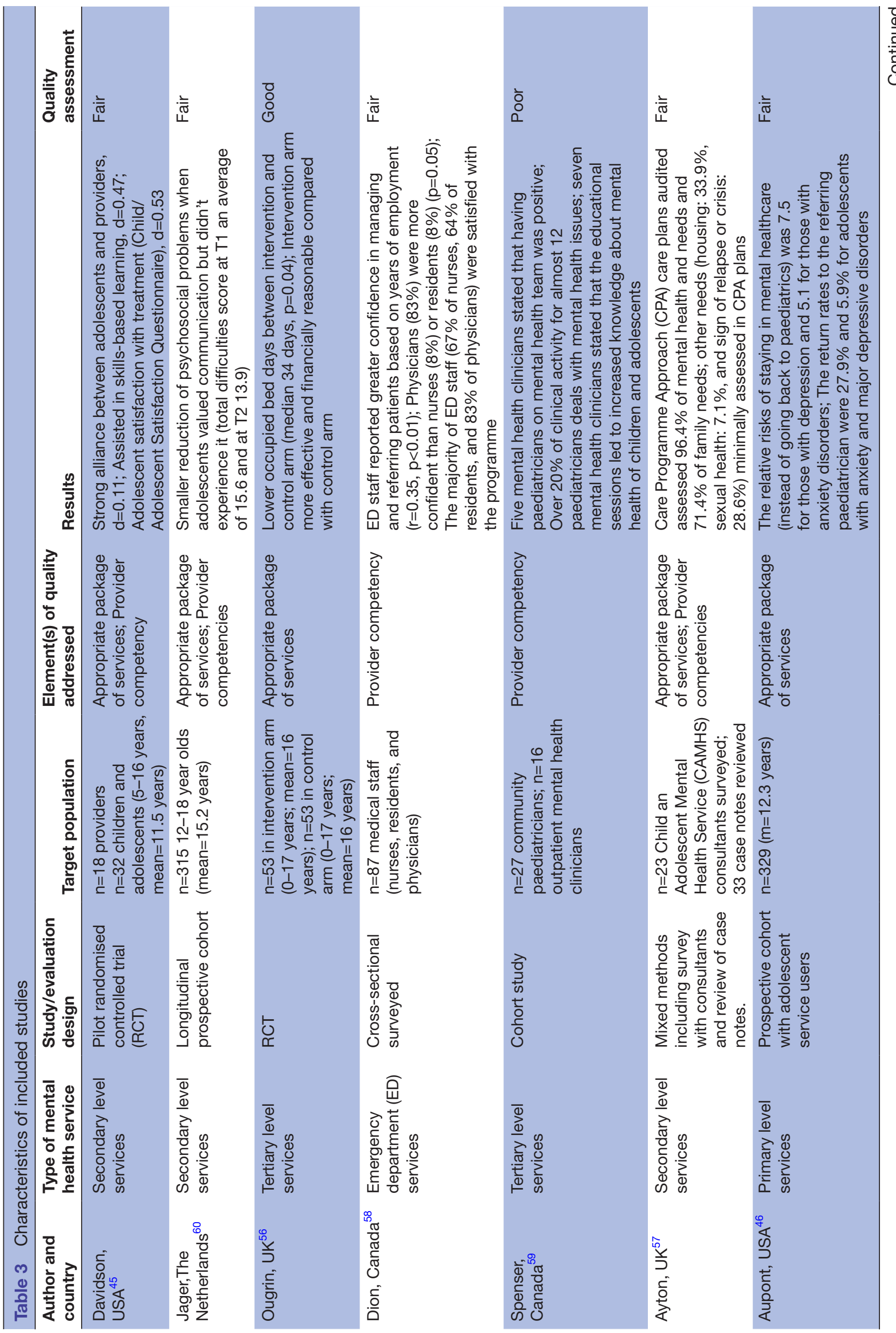



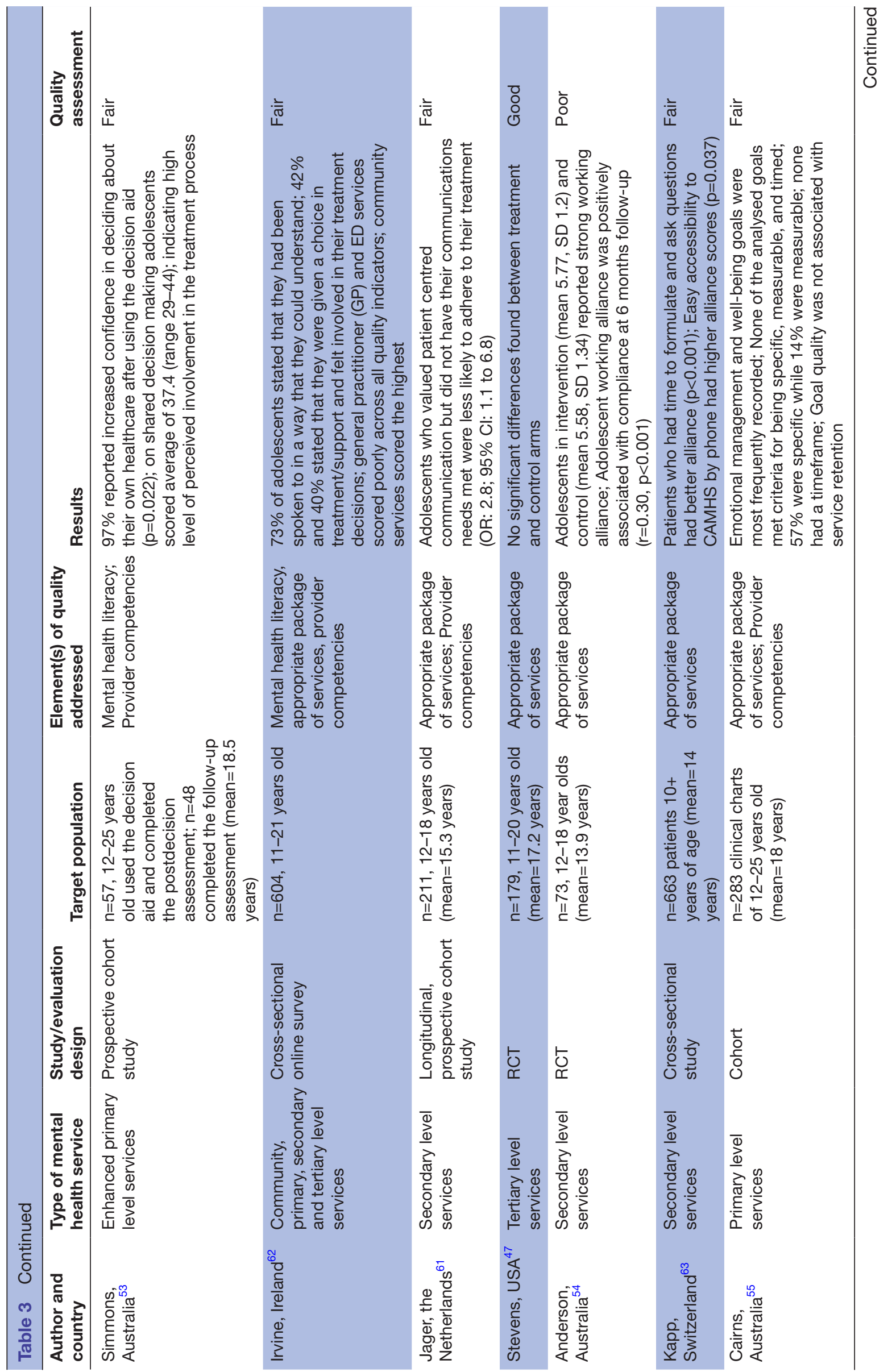

믕

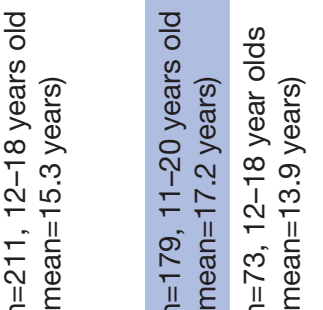

II

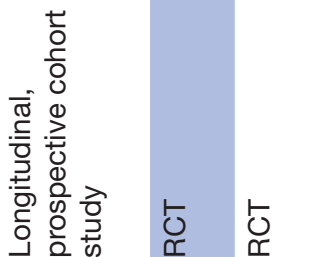

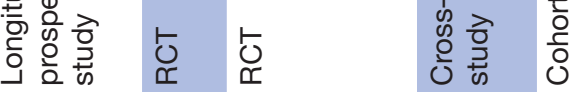
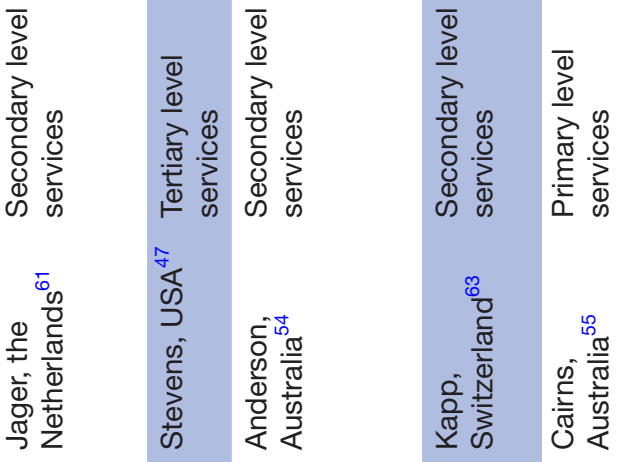


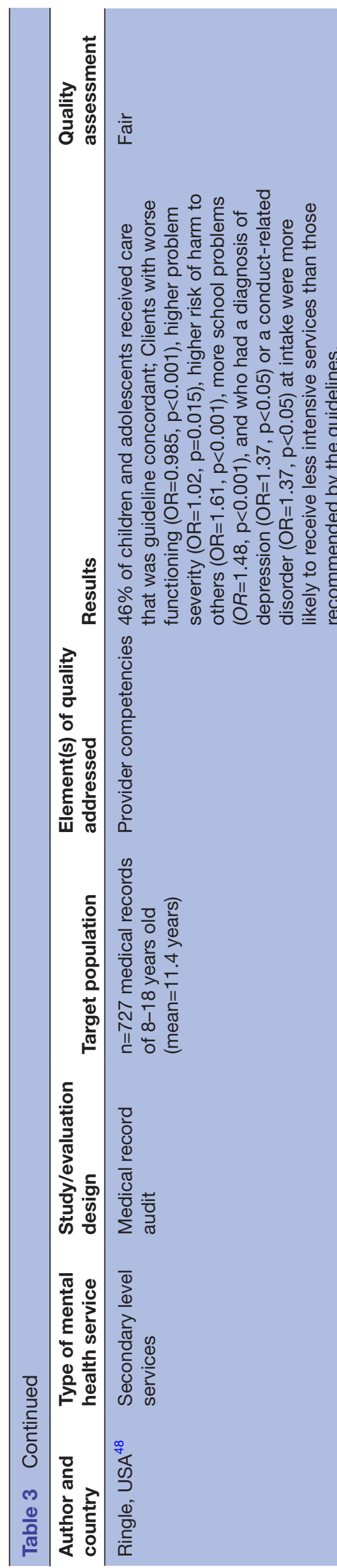

:

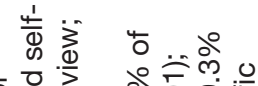

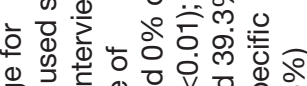
ब.

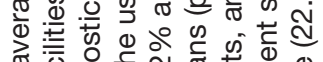
更 人ั 员

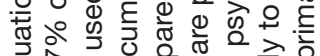

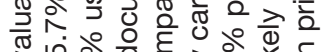

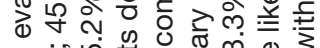
के î

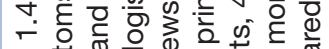
훙 ? है 要 क人

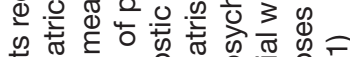

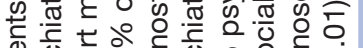

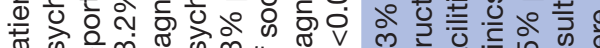

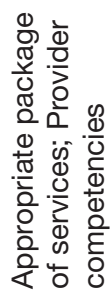

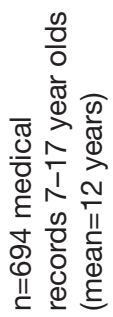

몽 윰

$\sum^{\infty} \frac{0}{\sigma}$

당

$\overbrace{\frac{\pi}{9}}^{\infty}$

흔 $\frac{2}{\frac{\pi}{0}}$

$\times$

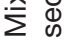

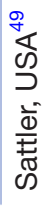

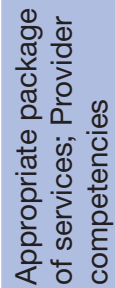

흥

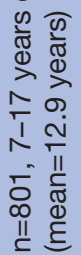

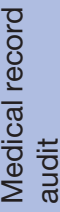

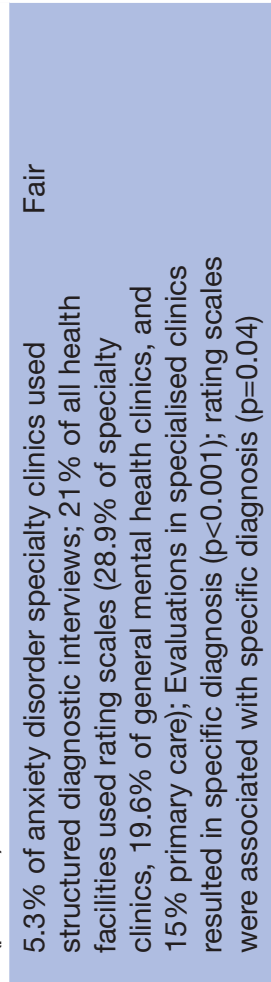

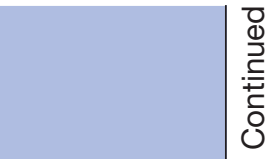<smiles>Oc1ccccc1</smiles>

๕

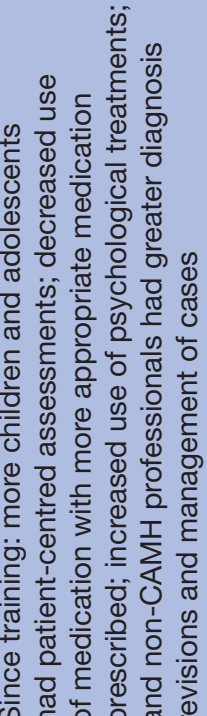

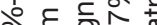
iी 응

다 $\varepsilon$

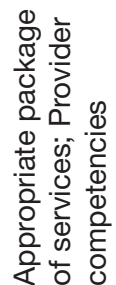

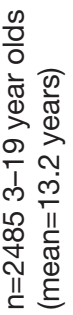

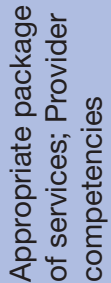

$\frac{0}{0}$
$\frac{0}{0}$
$\frac{0}{0}$
$\frac{0}{2}$
0
0
11
11

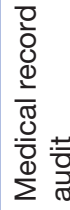

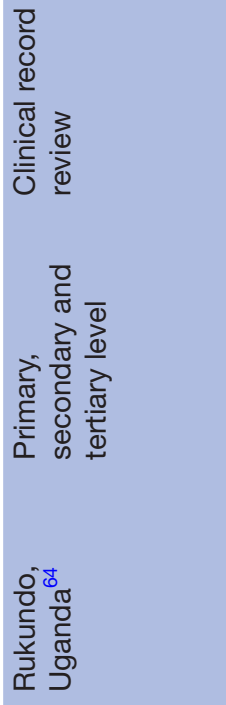




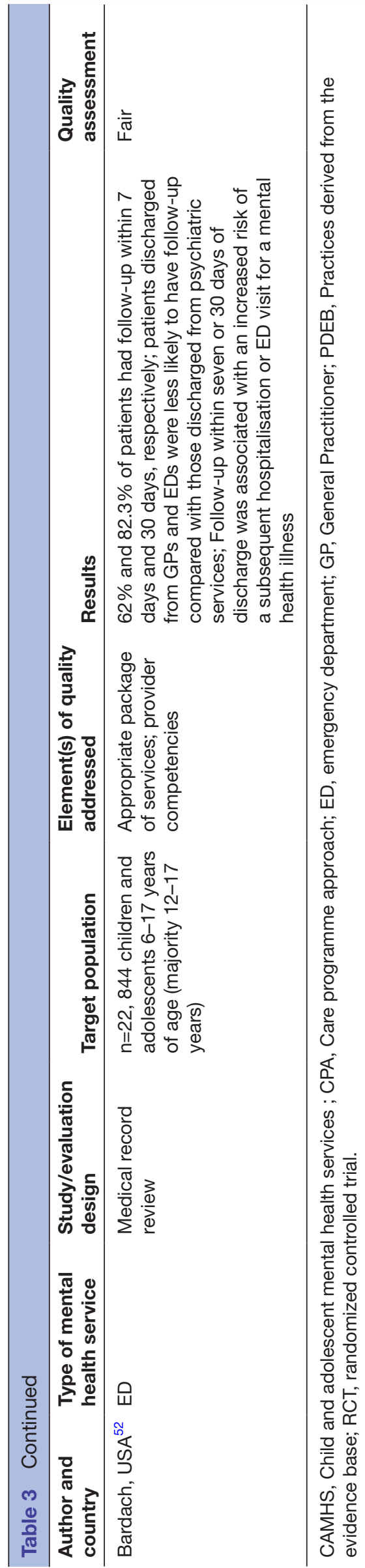

\section{Study characteristics and settings}

The majority of studies were conducted in high-income countries, namely the USA (eight studies), ${ }^{45-52}$ Australia (three studies) ${ }^{53-55}$ UK (two studies), ${ }^{56}$ Canada (two studies), ${ }^{58} 59$ the Netherlands (two studies) ${ }^{6061}$ Ireland $^{62}$ and Switzerland (one study). ${ }^{63}$ One study was conducted in Uganda. ${ }^{64}$ Most of the studies focused on evaluating or assessing the provision of services that are appropriate for adolescents (15 studies) and enhancing provider competencies ( 15 studies), with a minority focused on increasing adolescents' mental health literacy (two studies).

The services ranged from emergency, ${ }^{52} 58$ to primary level $^{46} 495052535562$ 64; secondary level mental health services $^{4548-52545760-64}$ and tertiary level services. ${ }^{475256596264}$

\section{Quality assessment}

The majority of the studies were assessed as 'fair' quality $(\mathrm{n}=16,80 \%)$; two $(10 \%)$ studies were assed as 'good' quality and two (10\%) were assessed as 'poor quality'. Studies rated as 'poor' mainly had lack of clarity about the methods and outcomes analysed, confounding and higher sources of bias. Ougrin $e t a l^{\tilde{6}}$ and Stevens $e t a t^{47}$ implemented studies that were rated as good quality. ${ }^{476}$ Both conducted randomised controlled trials in tertiary level facilities. They also experienced low drop-out rates, high adherence to the interventions, and consistently used valid and reliable measures. ${ }^{4756}$

\section{Conceptualising quality}

The majority of studies did not conceptualise quality. ${ }^{46} 475354$ 56-61 64 Where it was conceptualised, it was in reference to high quality care, defined as healthcare provider fidelity to evidence-based treatment models and adolescents' engagement in the treatment process (satisfaction and quality of engagement with therapists and adolescents) ${ }^{45}$; as quality indicators in terms of information and access, facilities and services and quality of care $^{62}$; as quality indicators in child and adolescent mental health services, specifically around patient satisfaction and quality engagement between the therapist and adolescent ${ }^{63}$; or follow-up after hospitalisation for a mental illness. ${ }^{52}$ Common themes within these studies were a focus on the processes of care and quality impacts (improved mental health and greater confidence of the health service and system). ${ }^{16}$

Other studies mentioned quality in relation to patientcentred communication or how providers adapt their communication style to meet the needs and preferences of their patients. ${ }^{61}$ Quality was also considered in relation to goal setting between the therapist and adolescent patient and whether these goals were specific, measurable, achievable, realistic/relevant and timely. ${ }^{55}$ The use of evidence-based assessments, practices and policies was another aspect of quality mentioned in some studies. ${ }^{48-5064}$ Other aspects of quality were linked to communication. These studies included: coordination of care between an in-patient mental health unit and a community service ${ }^{57}$; mental healthcare delivered through the emergency 


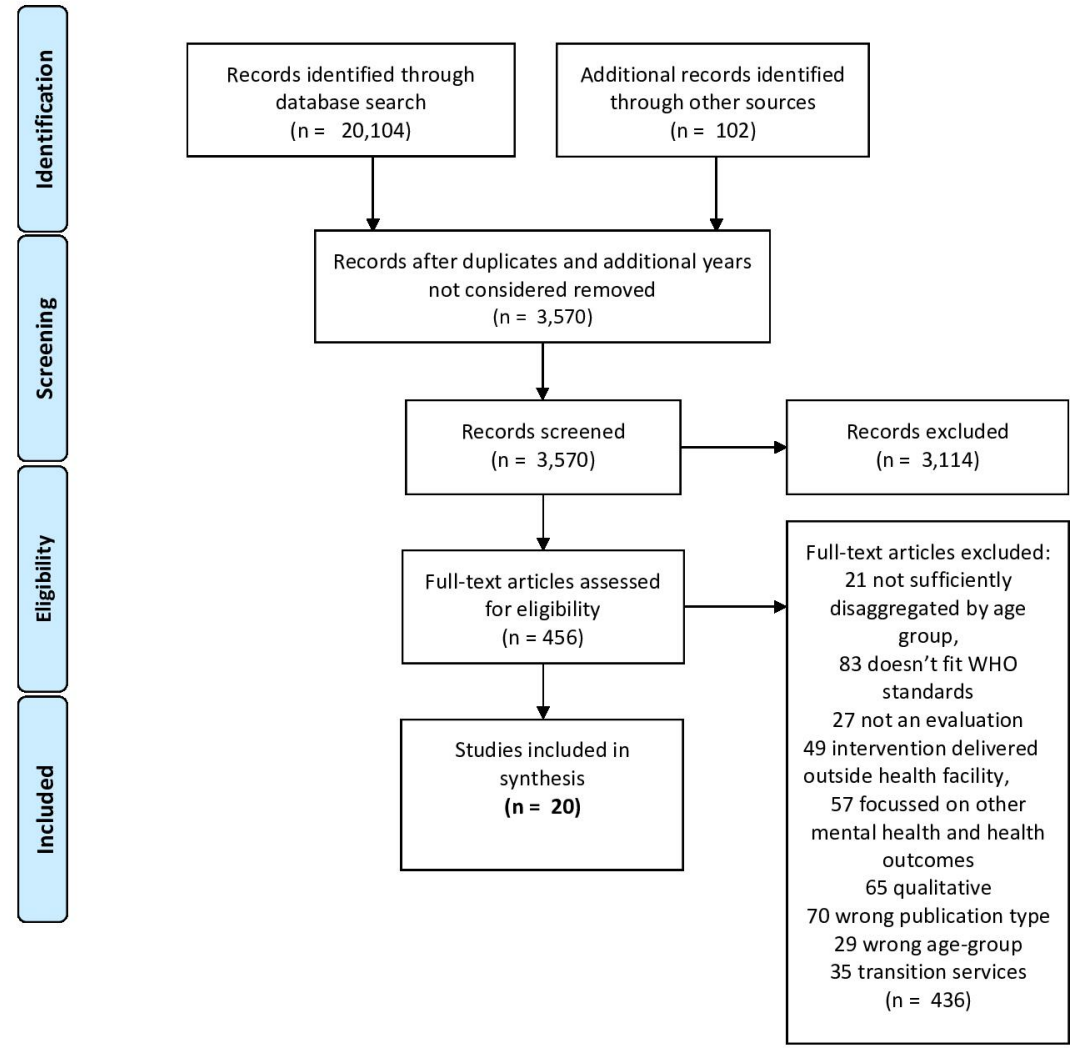

Figure 1 Flow diagram of studies.

department $(\mathrm{ED})^{58}$ and collaboration between family physicians and psychiatrists. ${ }^{59}$ Jager et $a l^{60}$ measured affective quality as a key component of patient-centred communication, however, this was not defined. ${ }^{60}$ The common theme that emerged from these studies is that they focused on foundations of quality care. ${ }^{16}$ Findings from the review are presented below by WHO quality standard. ${ }^{21}$

\section{Quality Standards}

Adolescent Mental Health Literacy

Two studies reported outcomes relevant to adolescent mental health literacy. One focused on an online decision aid for mental health services. ${ }^{53}$ Ninety-seven per cent of adolescents reported increased confidence and awareness in deciding about their own healthcare and involvement in the treatment process when exposed to an online decision aid $(\mathrm{p}=0.022) .{ }^{53}$ Another evaluated adolescents' experience with mental health services; specifically, whether they were given useful information to understand their mental health needs and if they had a choice in their treatment and/or support. ${ }^{62}$ EDs and general practitioner (GPs) scored poorly on these measures $(<50 \%$ of adolescents experiencing this) while more than $50 \%$ of adolescents reported that they had experienced this in community Child an Adolescent Mental Health Service (CAMHS) and inpatient care. ${ }^{62}$ The quality of evidence from these studies was fair.

\section{Appropriate Package of Services}

Fifteen of the 20 studies evaluated services that met the WHO standard for appropriate packages of services. ${ }^{21}$ Interventions that involved aspects of an appropriate package of mental health services were diverse and targeted the quality of engagement between the therapist and adolescent, ${ }^{45} 54556263$ patient-centred communication, ${ }^{6061}$ mental health service use, ${ }^{464764}$ linkages to mental health services, ${ }^{46}$ health facility culture and patient safety, ${ }^{57}$ clinician's assessment of diagnostic and treatment services ${ }^{49} 50$ and intensive community treatment. ${ }^{56}$ The quality of the evidence for the 15 studies was poor to good.

Five of the 15 studies ${ }^{45} 54556263$ reported improvements in the quality of engagement between therapist and adolescent patient, including the interaction, collaboration and bond. ${ }^{54}$ These included the use of a tablet-based application on trauma-focused cognitive behavioural therapy (TF-CBT) in the USA, ${ }^{45}$ an online CBT intervention in Australia, ${ }^{54}$ an outpatient child and adolescent mental health clinic in Switzerland, ${ }^{63}$ and the use of goal setting in Australia. ${ }^{55}$ Davidson et at $t^{45}$ evaluated a tabletbased application on TF-CBT, finding a small to medium effect size on developing therapeutic tasks $(\mathrm{d}=0.47)$ and a small effect size on therapeutic bond $(\mathrm{d}=0.11)$, with most adolescents satisfied with the intervention $(\mathrm{d}=0.53){ }^{45}$ Anderson $e t a b^{54}$ evaluated an online CBT intervention with minimal therapist contact, finding that greater therapeutic alliance led to greater adolescent adherence 
with treatment at 6-month follow-up $(\mathrm{r}=0.30, \mathrm{p}<0.001)$. Results also found that adolescents in both the intervention and control arm reported strong therapeutic alliance. ${ }^{54}$ Irvine ${ }^{62}$ evaluated adolescents' experience at different types of health facilities; specifically, whether they felt involved in the decisions that were made about their treatment plan and if they found the support to be helpful ${ }^{62} ; 16 \%, 30 \%, 36 \%$ and $42 \%$ of adolescents stated that they felt involved in decisions about their care from in-patient facilities, EDs, community CAMHS and GPs, respectively, and $34 \%, 39 \%, 44 \%$ and $45 \%$ felt the support they received was helpful from EDs, in-patient care, GPs and community CAMHS, respectively. ${ }^{62}$

Two of the 15 studies $^{60}{ }^{61}$ focused on patient-centred communication in the Netherlands, finding that adolescents who did not experience patient-centred communication were less likely to adhere (OR: 2.8, 95\% CI 1.1 to 6.8 ) and have confidence (OR $4.5,95 \%$ CI 1.8 to 11.6 ) in their course of treatment. ${ }^{61}$ They also were less likely to experience a significant reduction in their mental health problems, compared with those who experienced patientcentred communication. ${ }^{60}$

One study evaluated mental health service use through a telephone support service (TSS) intervention in the USA $^{47}$ The study found no difference in mental healthcare utilisation $(p=0.65)$ between adolescents in the intervention and those in usual care ${ }^{47}$ Another study evaluated referrals between paediatric care to mental health services through the Targeted Child Psychiatric Service programme in the USA. The programme enables access to specialised mental health services for adolescents with mental health conditions from paediatric primary care, ensuring long-term management in the most appropriate healthcare setting. Results showed that adolescents with depression and anxiety required continued access to specialised mental healthcare. ${ }^{46}$

One study ${ }^{57}$ evaluated health facility culture and patient safety with the Care Programme Approach (CPA), which ensures that children and adolescent patients are involved in all aspects of their mental healthcare in the UK. Patient safety was found to be an issue. In fact, unplanned discharge (ie, self-discharge, tribunal discharge or commissioning pressure to discharge) was the most common problem due to siloed rather than collaborative, decision making. Other challenges were limited collaboration between early intervention, education, and CAMHS teams; and a lack of joint protocols on the CPA and discharge between organisations. ${ }^{57}$

Two studies in the USA focused on the use of structured interviews, symptom rating scales, and Diagnostic and Statistical Manual of Mental Disorders diagnostic criteria in primary, secondary, and tertiary level services. ${ }^{49} 50$ Results showed that structured diagnostic interviews were more likely to be used by psychiatrists and psychologists compared with general physicians $(\mathrm{p}<0.01){ }^{49}$

One study examined whether a supported discharge service (SDS), or intensive community treatment, would be more beneficial and cost-effective than usual care among adolescents. ${ }^{56} \mathrm{~A}$ significant difference in the overall number of bed-days from the SDS arm was found at 6 months (median 34 days, $\mathrm{p}=0.04$ ) compared with usual care. The SDS was found to have at least $50 \%$ probability of being cost-effective in comparison to usual care and willingness to pay for outcome improvements (the incremental cost effectiveness ratio was -£991), or the cost per life year gained. ${ }^{56}$

\section{Providers' competencies}

Fifteen studies included outcomes relevant to healthcare provider competency. They focused on confidence in managing and referring adolescents with mental health issues ${ }^{58}$ greater collaboration between paediatricians and mental health clinicians, ${ }^{59}$ use of evidence-based practices, ${ }^{48-52}$ use of a tablet to facilitate adolescent patient engagement in therapy, ${ }^{45}$ provision of information ${ }^{53} 60-62$ and implementation of care models and plans. ${ }^{465764}$ The quality of evidence for the fifteen included studies ranged from poor to fair.

In evaluating confidence of referring adolescents with mental health patients, Dion $e t a l^{58}$ found that training through a Crisis Intervention Programme increased ED staff confidence in managing and triaging patients $(\mathrm{r}=0.35, \mathrm{p}<0.01)$ in Canada. ${ }^{58}$ Another study evaluated collaboration between paediatricians and outpatient mental health clinicians in Canada. Results showed a positive effect on patient care with a paediatrician on the mental health team. ${ }^{59}$

Five studies evaluated the use of evidence-based practices and guidelines in adolescent mental health services. ${ }^{48-51}$ Higa-McMillan et $a{ }^{\tilde{p}^{1}}$ found that the most commonly used evidence-based practices for adolescents with anxiety disorders included cognitive, psychoeducational, relaxation and modelling. ${ }^{51}$ In a USA study, the authors found that patients were more likely to receive less intensive services if they had poorer functioning, greater problem severity, greater risk of harm to others and greater school problems, with a diagnosis of depression or conduct disorder than guideline recommended. ${ }^{48}$ As part of the Children's Core Set of quality measures, Bardach et $a \tilde{l}^{2}$ evaluated the follow-up after hospitalisation for mental illness at 7 and 30 days for children and adolescents (aged 6-17 years old) in the USA. Results showed that $62 \%$ and $82.3 \%$ of patients were followed up within 7 and 30 days. Adolescent patients were more likely to be followed-up after discharge from psychiatric units and hospitals compared with those from general medical or surgical units. ${ }^{52}$

A 2-year child and adolescent mental health training programme for healthcare providers (psychiatric clinical officers, psychologists, psychiatric nurses, general nurses, occupational therapists, etc) was implemented in Uganda. ${ }^{64}$ Medical records were reviewed annually over 6 years, finding that a greater number of children and adolescents were receiving thorough patient-centred assessments; a reduction in medication prescription; an increase in the use of psychological treatments and 
greater management of cases by non-CAMHS professionals after the intervention. ${ }^{64}$

Two studies in the Netherlands found that adolescents who did not experience patient-centred communication were less likely to understand (OR: $3.7,95 \%$ CI 1.5 to 9.0$)^{60}{ }^{61}$ (OR: $3.1,95 \%$ CI 1.1 to 8.5$)^{61}$ their course of treatment. Similarly, through the use of an online decision aid, $93 \%$ of participants were more likely to make a healthcare decision that was guideline concordant $(\mathrm{p}=0.004)$ and consistent with their preferences. ${ }^{53}$

\section{DISCUSSION}

To our knowledge, this is the first review that has attempted to evaluate the quality of adolescent mental health services. ${ }^{21}$ A total of 20 studies were identified, overwhelmingly from high-income countries. Fifteen studies focused on packages of services, 15 on healthcare provider competency and two on mental health literacy. There was limited evidence ${ }^{53}$ of an intervention improving mental health, however, we cannot conclusively state this was effective.

Despite the large contribution of mental health conditions to the global burden of disease in adolescents and the need for quality mental healthcare services, we found that most studies lacked a formal conceptualisation of quality and did not have a clear framework or definition of quality. There were a variety of instruments used to measure quality and its indicators. Our understanding of quality in mental health services, as well as the generalisability of our findings, is therefore limited. Our findings also indicate a large service gap and suggests that there is a need to not only develop and standardise a definition of what constitutes quality adolescent mental healthcare, but also develop and standardise methods that measure quality in adolescent mental healthcare.

It should be noted that the WHO Global Standards were developed through a rigorous process. ${ }^{41}$ This involved a needs assessment, the development of the Standards, consultations with experts, assessing the usability of the Standards through regional consultations and a country field test. ${ }^{41}$ The WHO includes an implementation guide at the national, district and facility levels that identify actions needed to implement the Standards. ${ }^{21}$ The majority of studies were conducted by universities in health facility settings. In reviewing the implementation guide, healthcare provider training and use of decision support tools at the health facility were the actions most relevant. ${ }^{21}$ However, it was unclear the level of involvement of the health facility manager in the studies and whether there was an uptake of the intervention by the health facility after study completion. At the same time, there is a lack of peer-reviewed evidence on the implementation and evaluation of these standards, as well as a lack of specific and contextualised indicators to evaluate and monitor the Standards. This illustrates a gap between the literature and the Standards. The WHO (2015) does recognise that not all Standards will be implemented, and that the standards were made to be evaluated and developed further once adapted and implemented at the national and regional levels. ${ }^{41}$

There are several challenges to providing quality care within adolescent mental health services, including stigmatising attitudes and behaviours about treatment seeking, service provision and utilisation, ${ }^{65-68}$ the lack of professional expertise, ${ }^{22-24}$ and the current diseasebased model of medicine. ${ }^{20}$ Also, quality in mental health services has received little attention in relationship to adolescents. ${ }^{16}$ Indeed, stigma is a significant barrier to the availability and delivery of quality mental health services within communities. ${ }^{13}$ It has been posited that stigma occurs at the structural (organisation, resources, quality standards), interpersonal (the quality of engagement between the healthcare provider and adolescent, patient safety) and intraindividual levels (healthcare providers unwilling to assess adolescent mental health conditions, adolescents unwilling to seek mental healthcare services). ${ }^{69} 70$ This failure in quality prevents adolescents from seeking and continuing care for mental health conditions due to perceived stigma. ${ }^{65-69} 71$ It points to a need for mental health literacy among healthcare providers. Quality mental health services cannot be achieved without healthcare providers having a reasonable understanding of adolescent mental health. This needs to start with healthcare provider training and preservice education. $^{71}$

Apart from one study from Uganda, ${ }^{47}$ all of the studies were from high-income countries, illustrating an important gap in the literature within low-income and-middle-income countries (LMICs) around quality of adolescent mental health services. This could reflect service and research gaps in all aspects of mental health in LMIC, ${ }^{72-74}$ as well as different ways in which mental health is conceptualised in LMICs at the national and local levels. ${ }^{20}$ It may also reflect the continued orientation in LMICs to more acute health conditions rather than in response to complex conditions that require long-term care, such as mental health conditions. ${ }^{16}{ }^{20}$ Patel and Saxena ${ }^{20}$ argue that mental health conditions do not follow the typical disease-based model of medicine, and that a 'one size fits all' approach does not work. ${ }^{20}$ This is particularly the case for subsyndromal or early onset mental health conditions which may not readily fit with diagnostically oriented services. ${ }^{68}$

There have been efforts to overcome these challenges, as identified in table 4 . While the majority of these studies focused on generic healthcare for adolescents, their findings are equally relevant for adolescent mental healthcare.

Arguably, a good starting point for measuring quality in adolescent mental healthcare services would be a more scalable combination of the youth-friendly guideline driven care developed by Ambresin $e t a l^{28}$ and the quality standards developed by Sayal et al. ${ }^{32}$ The same investments that promote quality in other age groups will be similarly valuable for adolescents, but greater specificity and focus is required around the health service aspects 
Table 4 Frameworks to address quality in adolescent health services

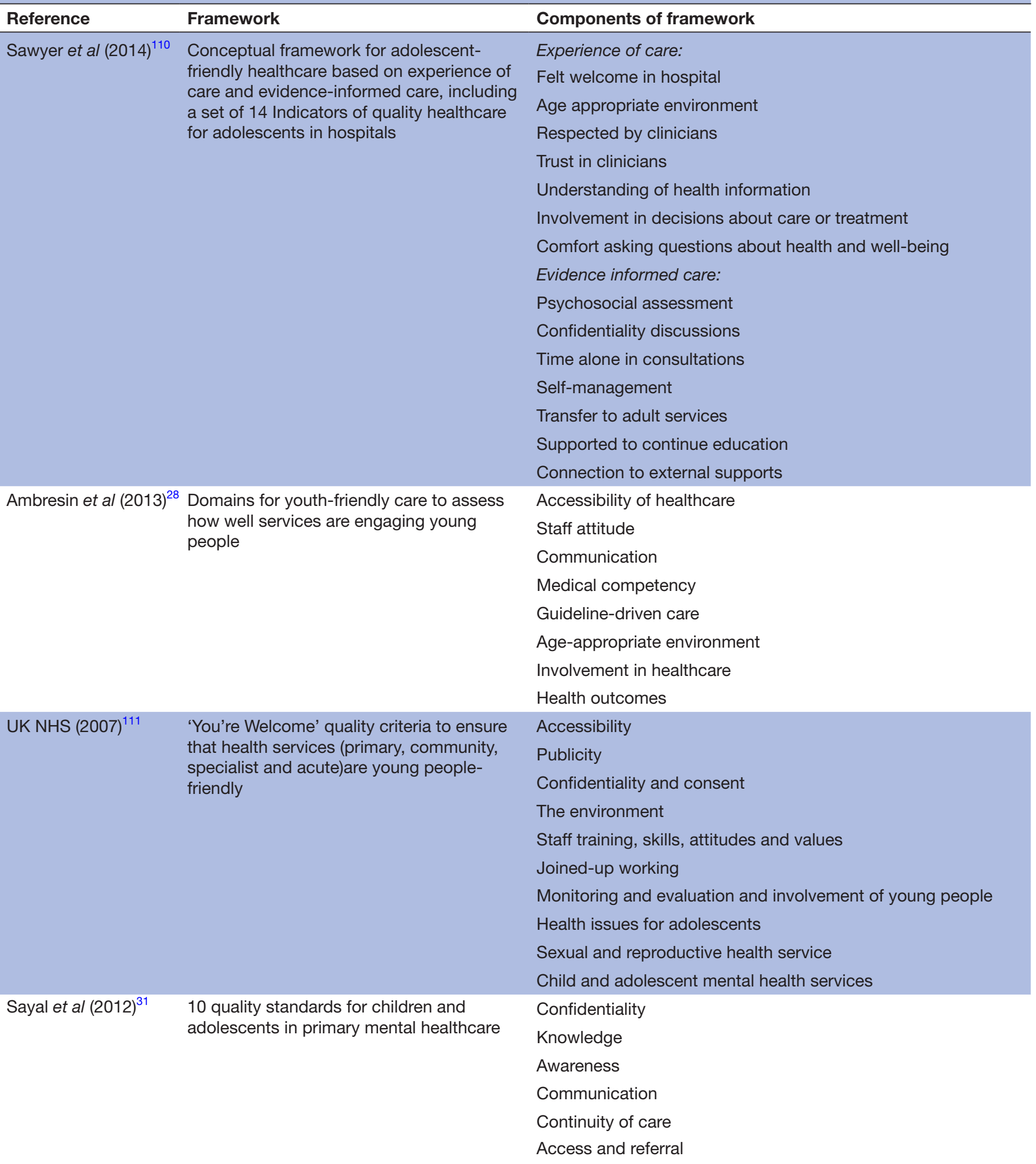

of engagement, communication and confidentiality. The studies identified in our review examined aspects of engagement and communication, but interestingly, did not explore confidentiality.

The findings from our review should be appreciated in light of the broader challenges to quality in adolescent mental health services as described above. Regarding adolescent mental health literacy, we found that a youth decision aid helped young people make evidenceinformed decisions about their treatment, feel engaged in the process, and increased treatment adherence. ${ }^{53}$ Previous literature has found similar results, with patients 
reporting increased involvement in treatment decision making, increased knowledge about the treatment options and outcomes, and greater comfort making decisions. ${ }^{75}$ As a foundation for quality, adolescents' knowledge shapes the way mental health services respond to them, and helps adolescents hold these services to account. ${ }^{16}$ For packages of services, the quality of engagement between the adolescent and therapist was found to lead to positive outcomes. ${ }^{76} 77$ The quality of the patient-therapist relationship has led to greater treatment efficacy, ${ }^{78}$ increased autonomy, patient alliance and engagement, and greater favourable outcomes. ${ }^{54} 79$ It ensures that the adolescent's perspective is included, that they consent and assent to their treatment plan, ${ }^{80}$ and that they can address problems throughout the treatment process. ${ }^{81}$ Evidence from the UK has shown that current services are not adequate for young people's mental health needs, ${ }^{82-84}$ with youth reporting that they should be more engaged in the design of mental health services. From the studies on provider competency, we found that training general healthcare providers about adolescent mental health conditions helped build their confidence and knowledge when treating adolescents. ${ }^{58964}$ This aligns with previous literature as healthcare providers reported confidence, knowledge and a lack of specialised providers as barriers to care. ${ }^{8586}$ Provider competency is a foundation and process of care. ${ }^{16}$ Adolescent mental healthcare providers require adequate clinical education and training on adolescent mental health. They also should provide evidence-based treatment, communicate clearly, ensure confidentiality and autonomy, promote timely and effective care and instil confidence in their adolescent patients that their conditions are being correctly detected and managed. ${ }^{16}$

The quality of evidence, assessed using the NIH Quality Assessment Tool, ranged from poor to good, and included various limitations in study design which could bias the results of the review. Furthermore, there was variation in the approach and tools used within evaluations, the content of the service, as well as the sample size. Certainly, within the three standards we systematically reviewed, it is not possible to identify the most effective standard of quality or service delivery method, as conforms to the WHO Global Standards. ${ }^{21}$

\section{Recommendations}

We have several recommendations for further research on quality in adolescent mental health services to promote improved mental health outcomes. These recommendations are particularly important in light of the reported increase in adolescent mental health conditions associated with the COVID-19 pandemic. ${ }^{87-91}$

- First, to promote comparability, understanding and inform data collection, agreement around a developmentally-appropriate definition of quality would inform methods to measure quality in adolescent mental health services across different contexts.

- Second, collaborative research efforts, including the active participation of adolescents in this process, are needed to strengthen the evidence on quality in adolescent mental health services, especially in LMICs. This includes research on adolescent mental health needs (particularly those exposed to daily adversity), research that articulates and tests the types of services that are best able to respond to their needs, knowledge of effective strategies to improve the quality of mental health services, including efforts to upskill the capabilities of all healthcare providers, not just mental health professionals, around adolescent mental health, ${ }^{92}$ and evidence on the sustainability and effectiveness of what quality interventions to scale up through the health system, including psychotropic drugs and telehealth interventions. Furthermore, future studies should focus on psychotic disorders, which are also prevalent among adolescents and for which little evidence on quality of care is available.

- Third, health services need to proactively engage adolescents about their health needs, including mental health needs, and to ensure that they are informed about confidential services that are available to them, including vulnerable and at-risk adolescents.

- Fourth, to reduce stigma and close the well described treatment gap, ${ }^{93-95}$ there needs to be greater investment in integrating adolescent mental health services into primary healthcare and training of nonspecialised healthcare providers on adolescent mental health. This review shows that stigma negatively influences the quality of adolescent mental health services, which affirms the value of incorporating stigma reduction indicators into quality of care measures, as advocated by Knaak et al. ${ }^{96}$ Cost-effectiveness analyses could help inform governments about the benefits to be gained when better mental health is reflected in higher school completion and regular employment.

\section{Study limitations}

This review should be interpreted within the context of a number of limitations. We recognise that the WHO Global Standards quality framework is but one way of categorising quality. Leslie $e t a \ell^{97}$ warn that despite recent initiatives and greater focus on quality in healthcare, the various concepts and frameworks used to define and measure quality have led to 'inconsistent assessments and incomparable investments, leaving researchers and policymakers without direction, ${ }^{97}$ We recognise that beyond mental health services, the focus of this review, that there are various resources that can address adolescent mental health. This includes parenting interventions, which have been found to improve the mental health of adolescents ${ }^{91}$ and school-based mental health interventions, which have also been found to contribute to improved health. ${ }^{22}$ We also appreciate that an important aspect of quality care is continuity of care. For adolescents with persisting mental health issues, the transition from child or adolescent oriented services to adult oriented mental health services is a particularly important aspect of continuity of care. While this was beyond the scope of this review, it 
is consistent with many adolescent services now using an extended definition of adolescence ${ }^{98}$ up to 24 years.

None of the included studies focused on the quality of psychotropic drug prescriptions or the use of telehealth, as this was beyond the scope of the review and a limitation. Psychotropic drug prescriptions are one component of treatment for severe adolescent mental health conditions, with evidence from the USA in 2013 finding that $7 \%$ of adolescent participants were treated with psychotropic medication. ${ }^{99}$ Despite this, high-quality evidence on the long-term effectiveness and safety of these medications for adolescents is limited, varying by condition and medication class. ${ }^{99-101}$ The use of telehealth for mental health conditions has a long history, but has been growing in recent years as an accessible, efficient and cost-effective alternative to face-to-face consultations. ${ }^{102}$ Evidence has found that telehealth is associated with patient satisfaction and is effective in evaluating and analysing mental health conditions. ${ }^{102}$ In our review, we identified a number of studies that used different elements of telehealth. More recently, there has been appreciation of the particular benefits of telehealth within the context of the COVID-19 pandemic, including in low-resource settings. Evidence has found that it is associated with reduction in stigma and a higher participation rate among this age group, which may reflect adolescents ease with technology. ${ }^{403-105}$ However, telehealth is also not without challenges, including around privacy, confidentiality, safety and equitable service use. ${ }^{103} 104$ Limited access to the internet is a particular challenge to equitable telehealth. Telehealth sessions are typically easier to record which, in the context of informed consent, provides one mechanism to assess quality. Further research to identify which patients would most benefit from in-person visits or telehealth is indicated for common mental health conditions. ${ }^{104106}$

\section{CONCLUSIONS}

This review indicates the lack of consensus on quality in mental health services, with most of the identified studies failing to conceptualise quality at all. Many challenges remain around improving the quality of mental healthcare for adolescents.

Correction notice This article has been corrected since it was first published. The correct licence type is CC BY.

Twitter Susan M. Sawyer @SusanSawyer01

Contributors MQ-D led the study design, data searches, data extraction, quality appraisal, synthesis and drafted the manuscript. KJR contributed to the design, data extraction, quality appraisal and writing of the manuscript. LK and DD provided significant and critical contribution to the conceptualisation, design and interpretation of findings. SS critically reviewed the manuscript and offered key intellectual input to the synthesis and interpretation of findings. RC critically reviewed the manuscript and offered important intellectual input.

Funding This research received no specific grant from any funding agency in the public, commercial or not-for-profit sectors. KJR is supported by an Economic Social Research Council (ESRC) PhD studentship through the UBEL DTP (kr0001).

Competing interests None declared.

Patient consent for publication Not required.

Provenance and peer review Not commissioned; externally peer reviewed.
Data availability statement Data sharing not applicable as no datasets generated and/or analysed for this study. Not applicable.

Supplemental material This content has been supplied by the author(s). It has not been vetted by BMJ Publishing Group Limited (BMJ) and may not have been peer-reviewed. Any opinions or recommendations discussed are solely those of the author(s) and are not endorsed by BMJ. BMJ disclaims all liability and responsibility arising from any reliance placed on the content. Where the content includes any translated material, BMJ does not warrant the accuracy and reliability of the translations (including but not limited to local regulations, clinical guidelines, terminology, drug names and drug dosages), and is not responsible for any error and/or omissions arising from translation and adaptation or otherwise.

Open access This is an open access article distributed in accordance with the Creative Commons Attribution 4.0 Unported (CC BY 4.0) license, which permits others to copy, redistribute, remix, transform and build upon this work for any purpose, provided the original work is properly cited, a link to the licence is given, and indication of whether changes were made. See: https://creativecommons.org/ licenses/by/4.0/.

ORCID iD

Meaghen Quinlan-Davidson http://orcid.org/0000-0002-7875-3753

\section{REFERENCES}

1 Kessler RC, Amminger GP, Aguilar-Gaxiola S, et al. Age of onset of mental disorders: a review of recent literature. Curr Opin Psychiatry 2007;20:359-64.

2 Jones PB. Adult mental health disorders and their age at onset. $\mathrm{Br} \mathrm{J}$ Psychiatry Supp/ 2013;54:s5-10.

3 Mokdad AH, Forouzanfar MH, Daoud F, et al. Global burden of diseases, injuries, and risk factors for young people's health during 1990-2013: a systematic analysis for the Global Burden of Disease Study 2013. The Lancet 2016;387:2383-401.

4 Patton GC, Sawyer SM, Santelli JS, et al. Our future: a Lancet commission on adolescent health and wellbeing. Lancet 2016;387:2423-78.

5 WHO. Health for the world's adolescents: A second chance in the second decade. Geneva: World Health Organization, 2014.

6 Kessler RC, Berglund P, Demler O, et al. Lifetime prevalence and age-of-onset distributions of DSM-IV disorders in the National comorbidity survey replication. Arch Gen Psychiatry 2005;62:593-602.

7 IHME. Global burden of disease compare: 2016 prevalence. Seattle: Institute for health metrics and evaluation, 2016. https://vizhub. healthdata.org/gbd-compare/

8 Alisic E, Zalta AK, van Wesel F, et al. Rates of post-traumatic stress disorder in trauma-exposed children and adolescents: metaanalysis. Br J Psychiatry 2014;204:335-40.

9 Kalisch R, Baker DG, Basten U, et al. The resilience framework as a strategy to combat stress-related disorders. Nat Hum Behav 2017;1:784-90.

10 Global Burden of Disease Study 2013 Collaborators. Global, regional, and national incidence, prevalence, and years lived with disability for 301 acute and chronic diseases and injuries in 188 countries, 1990-2013: a systematic analysis for the global burden of disease study 2013. Lancet 2015;386:743-800.

11 Yin X, Guven N, Dietis N. Stress-based animal models of depression: do we actually know what we are doing? Brain Res 2016;1652:30-42.

12 de Vries G-J, Olff M. The lifetime prevalence of traumatic events and posttraumatic stress disorder in the Netherlands. J Trauma Stress 2009;22:259-67.

13 Kessler RC, Aguilar-Gaxiola S, Alonso J, et al. Trauma and PTSD in the who world mental health surveys. Eur J Psychotraumatol 2017;8:1353383-83.

14 UNICEF. COVID-19 and children: UNICEF data hub NYC UNICEF, 2020. Available: https://data.unicef.org/covid-19-and-children/\#

15 Horesh D, Brown AD. Traumatic stress in the age of COVID-19: a call to close critical gaps and adapt to new realities. Psychol Trauma 2020;12:331-5.

16 Kruk ME, Gage AD, Arsenault C, et al. High-Quality health systems in the sustainable development goals era: time for a revolution. Lancet Glob Health 2018;6:e1196-252.

17 IOM. Crossing the quality chasm: a new health system for the 21st century. Washington, DC: National Academies Press (US), 2001.

18 WHO. Quality of care: a process of making strategic choices in health systems. Geneva: World Health Organization, 2006. 
19 WHO. Making health services adolescent friendly: developing national quality standards for adolescent friendly health services. Geneva: World Health Organization, 2012.

20 Patel V, Saxena S. Achieving universal health coverage for mental disorders. BMJ 2019;366:14516-I16.

21 UNAIDS WHO. Global standards for quality health care services for adolescents: a guide to implement a standards-driven approach to improve the quality of health care services for adolescents. Geneva: World Health Organization, 2015.

22 Rickwood D, Deane FP, Wilson CJ. Young people's help-seeking for mental health problems. AeJAMH 2005;4

23 Saraceno B, van Ommeren M, Batniji R, et al. Barriers to improvement of mental health services in low-income and middleincome countries. The Lancet 2007;370:1164-74.

24 Aguirre Velasco A, Cruz ISS, Billings J, et al. What are the barriers, facilitators and interventions targeting help-seeking behaviours for common mental health problems in adolescents? A systematic review. BMC Psychiatry 2020;20:293.

25 Jorm AF. Mental health literacy: empowering the community to take action for better mental health. Am Psychol 2012;67:231-43.

26 WHO. Adolescent mental health Geneva: WHO 2020, 2019. Available: https://www.who.int/news-room/fact-sheets/detail/ adolescent-mental-health [Accessed 1 Jul 2019].

27 World Health O. Quality assessment guidebook: a guide to assessing health services for adolescent clients. Geneva: World Health Organization, 2009.

28 Ambresin A-E, Bennett K, Patton GC, et al. Assessment of youthfriendly health care: a systematic review of indicators drawn from young people's perspectives. J Adolesc Health 2013;52:670-81.

29 Lancet Global Mental Health Group, Chisholm D, Flisher AJ, et al. Scale up services for mental disorders: a call for action. Lancet 2007;370:1241-52.

30 Barry MM, Clarke AM, Jenkins R, et al. A systematic review of the effectiveness of mental health promotion interventions for young people in low and middle income countries. BMC Public Health 2013;13:835.

31 Sayal K, Amarasinghe M, Robotham S, et al. Quality standards for child and adolescent mental health in primary care. BMC Fam Pract 2012;13:51.

32 McDonald CC, Deatrick JA, Kassam-Adams N, et al. Community violence exposure and positive youth development in urban youth. $J$ Community Health 2011;36:925-32.

33 Slopen N, Fitzmaurice GM, Williams DR, et al. Common patterns of violence experiences and depression and anxiety among adolescents. Soc Psychiatry Psychiatr Epidemiol 2012;47:1591-605.

34 Finkelhor D, Ormrod RK, Turner HA. Poly-victimization: a neglected component in child victimization. Child Abuse Negl 2007;31:7-26.

35 Cooley-Quille M, Boyd RC, Frantz E, et al. Emotional and behavioral impact of exposure to community violence in inner-city adolescents. J Clin Child Psychol 2001;30:199-206.

36 Buka SL, Stichick TL, Birdthistle I, et al. Youth exposure to violence: prevalence, risks, and consequences. Am J Orthopsychiatry 2001;71:298-310.

37 Hammack PL, Richards MH, Luo Z, et al. Social support factors as moderators of community violence exposure among inner-city African American young adolescents. J Clin Child Adolesc Psychol 2004;33:450-62.

38 Fitzpatrick S, Saraiya T, Lopez-Castro T, et al. The impact of trauma characteristics on post-traumatic stress disorder and substance use disorder outcomes across integrated and substance use treatments. J Subst Abuse Treat 2020;113:107976.

39 McGorry PD, Hartmann JA, Spooner R, et al. Beyond the "at risk mental state" concept: transitioning to transdiagnostic psychiatry. World Psychiatry 2018;17:133-42.

40 WHO. mhGAP: mental health gap action programme: scaling up care for mental, neurological and substance use disorders. Geneva: World Health organization, 2008.

41 Nair M, Baltag V, Bose K, et al. Improving the quality of health care services for adolescents, globally: a Standards-Driven approach. $J$ Adolesc Health 2015;57:288-98.

42 Moher D, Liberati A, Tetzlaff J, et al. Preferred reporting items for systematic reviews and meta-analyses: the PRISMA statement. BMJ 2009;339:b2535.

43 Endnote X9 [program]. London: Clarivate analytics 2019.

$44 \mathrm{NIH}$. Quality assessment tool for observational cohort and crosssectional studies. Washington, DC: National Institutes of health, 2014. https://www.nhlbi.nih.gov/health-topics/study-qualityassessment-tools
45 Davidson TM, Bunnell BE, Saunders BE, et al. Pilot evaluation of a tablet-based application to improve quality of care in child mental health treatment. Behav Ther 2019;50:367-379.

46 Aupont $\mathrm{O}$, Doerfler $\mathrm{L}$, Connor DF, et al. A collaborative care model to improve access to pediatric mental health services. Adm Policy Ment Health 2013;40:264-73.

47 Stevens J, Klima J, Chisolm D, et al. A trial of telephone services to increase adolescent utilization of health care for psychosocial problems. J Adolesc Health 2009;45:564-70.

48 Mora Ringle VA, Hickey JS, Jensen-Doss A. Patterns and predictors of compliance with utilization management guidelines supporting a state policy to improve the quality of youth mental health services. Child Youth Serv Rev 2019;96:194-203.

49 Sattler AF, Leffler JM, Harrison NL, et al. The quality of assessments for childhood psychopathology within a regional medical center. Psychol Serv 2019;16:596-604.

50 Sattler AF, Ale CM, Nguyen K, et al. Use of evidence-based assessments for childhood anxiety disorders within a regional medical system. Psychol Serv 2016;13:411-8.

51 Higa-McMillan C, Kotte A, Jackson D, et al. Overlapping and nonoverlapping practices in usual and evidence-based care for youth anxiety. J Behav Health Serv Res 2017;44:684-94.

52 Bardach NS, Doupnik SK, Rodean J, et al. Ed visits and readmissions after follow-up for mental health hospitalization. Pediatrics 2020;145:e20192872.

53 Simmons MB, Elmes A, McKenzie JE, et al. Right choice, right time: evaluation of an online decision aid for youth depression. Health Expect 2017;20:714-23.

54 Anderson REE, Spence SH, Donovan CL, et al. Working alliance in online cognitive behavior therapy for anxiety disorders in youth: comparison with clinic delivery and its role in predicting outcome. J Med Internet Res 2012;14:e88.

55 Cairns AJ, Kavanagh DJ, Dark F, et al. Goal setting improves retention in youth mental health: a cross-sectional analysis. Child Adolesc Psychiatry Ment Health 2019;13:31.

56 Ougrin D, Corrigall R, Poole J, et al. Comparison of effectiveness and cost-effectiveness of an intensive community supported discharge service versus treatment as usual for adolescents with psychiatric emergencies: a randomised controlled trial. Lancet Psychiatry 2018;5:477-85.

57 Ayton A, Meads G. The implementation of the care programme approach in the west midlands CAMHS: The impact of organisational diversity on patient safety - an extended audit. International Journal of Clinical Leadership 2013;17:185-200.

58 Dion J, Kennedy A, Cloutier P, et al. Evaluating crisis intervention services for youth within an emergency department: a view from within. Child Care in Practice 2010;16:241-56.

59 Spenser HR, Gillies A, Maysenhoelder H. The ChAT project: paediatricians and mental health clinicians: working together for the sake of the children. $J$ Can Acad Child Adolesc Psychiatry 2009;18:110-6.

60 Jager M, Reijneveld SA, Almansa J, et al. Less reduction of psychosocial problems among adolescents with unmet communication needs. Eur Child Adolesc Psychiatry 2017;26:403-12.

61 Jager M, Reijneveld SA, Metselaar J, et al. Discrepancies between adolescents' attributed relevance and experiences regarding communication are associated with poorer client participation and learning processes in psychosocial care. Patient Educ Couns 2014;97:332-8.

62 Irvine C. Reviewing mental health services and support for children and young people in Northern Ireland: a Rights-Based approach. Child Care in Practice 2020:1-11.

63 Kapp C, Perlini T, Jeanneret T, et al. Identifying the determinants of perceived quality in outpatient child and adolescent mental health services from the perspectives of parents and patients. Eur Child Adolesc Psychiatry 2017;26:1269-77.

64 Rukundo GZ, Nalugya J, Otim P, et al. A collaborative approach to the development of multi-disciplinary teams and services for child and adolescent mental health in Uganda. Front Psychiatry 2020;11:579417.

65 Mukolo A, Heflinger CA, Wallston KA. The stigma of childhood mental disorders: a conceptual framework. J Am Acad Child Adolesc Psychiatry 2010;49:92-198.

66 Gulliver A, Griffiths KM, Christensen H. Perceived barriers and facilitators to mental health help-seeking in young people: a systematic review. BMC Psychiatry 2010;10:113.

67 Radez J, Reardon T, Creswell C, et al. Why do children and adolescents (not) seek and access professional help for their mental health problems? A systematic review of quantitative and qualitative studies. Eur Child Adolesc Psychiatry 2021;30:183-211. 
68 Care Quality Commission. Review of children and young people's mental health services: Phase One supporting documentation: Summary of recent policy and literature. London: Care Quality Commission, 2017.

69 Corrigan P. How stigma interferes with mental health care. Am Psychol 2004;59:614-25.

70 JD L. Mental illness-related structural stigma: the downward spiral of systemic exclusion. Alberta, Canada: Mental Health Commission of Canada, 2013.

71 DuPont-Reyes MJ, Villatoro AP, Phelan JC, et al. Adolescent views of mental illness stigma: an intersectional lens. Am J Orthopsychiatry 2020;90:201-11.

72 Patton G, Temmerman M. Evidence and evidence gaps in adolescent health. Journal of Adolescent Health 2016;59:S1-3.

73 Das JK, Salam RA, Lassi ZS, et al. Interventions for adolescent mental health: an overview of systematic reviews. J Adolesc Health 2016;59:S49-60.

74 Juengsiragulwit D. Opportunities and obstacles in child and adolescent mental health services in low- and middle-income countries: a review of the literature. WHO South East Asia J Public Health 2015:4:110-22.

75 O'Connor AM, Légaré F, Stacey D. Risk communication in practice: the contribution of decision AIDS. BMJ 2003;327:736-40.

76 Hawley KM, Garland AF. Working alliance in adolescent outpatient therapy: youth, parent and therapist reports and associations with therapy outcomes. Child Youth Care Forum 2008;37:59-74.

77 Marker CD, Comer JS, Abramova V, et al. The reciprocal relationship between alliance and symptom improvement across the treatment of childhood anxiety. J Clin Child Adolesc Psychol 2013;42:22-33.

78 Anstiss D, Davies A, Out 'Reach. 'Reach Out, Rise Up': The efficacy of text messaging in an intervention package for anxiety and depression severity in young people. Child Youth Serv Rev 2015;58:99-103.

79 Gondek D, Edbrooke-Childs J, Velikonja T, et al. Facilitators and barriers to person-centred care in child and young people mental health services: a systematic review. Clin Psychol Psychother 2017;24:870-86.

80 Weithorn LA, Campbell SB. The competency of children and adolescents to make informed treatment decisions. Child Dev 1982;53:1589-98.

81 Langer DA, Jensen-Doss A. Shared decision-making in youth mental health care: using the evidence to plan treatments collaboratively. J Clin Child Adolesc Psychol 2018;47:821-31.

82 FoCaAPaFoGA P. Good mental health services for young people. London: Royal College of Psychiatrists, 2017.

83 L C. Working at the CAMHS/Adult interface: good practice guidance for the provision of psychiatric services to adolescents/young adults. London: Royal College of Psychiatrists, 2008.

84 Birchwood M, Singh SP. Mental health services for young people: matching the service to the need. Br J Psychiatry Suppl 2013;54:s1-2.

85 O'Brien D, Harvey K, Howse J, et al. Barriers to managing child and adolescent mental health problems: a systematic review of primary care practitioners' perceptions. Br J Gen Pract 2016;66:e693-707.

86 Kutcher S, Davidson S, Manion I. Child and youth mental health: integrated health care using contemporary competency-based teams. Paediatr Child Health 2009;14:315-8.

87 Loades ME, Chatburn E, Higson-Sweeney N, et al. Rapid systematic review: the impact of social isolation and loneliness on the mental health of children and adolescents in the context of COVID-19. J Am Acad Child Adolesc Psychiatry 2020;59:1218-39.

88 Thompson EC, Thomas SA, Burke TA, et al. Suicidal thoughts and behaviors in psychiatrically hospitalized adolescents pre- and postCOVID-19: a historical chart review and examination of contextual correlates. J Affect Disord Rep 2021;4:100100-00.

89 O'Sullivan K, Clark S, McGrane A, et al. A qualitative study of child and adolescent mental health during the COVID-19 pandemic in Ireland. Int J Environ Res Public Health 2021;18. doi:10.3390/ ijerph18031062. [Epub ahead of print: 2501 2021].

90 World Health Organization. The impact of COVID-19 on mental, neurological and substance use services: results of a rapid assessment. Geneva: World Health Organization, 2020: 36

91 de Figueiredo CS, Sandre PC, Portugal LCL, et al. COVID-19 pandemic impact on children and adolescents' mental health: biological, environmental, and social factors. Prog Neuropsychopharmacol Biol Psychiatry 2021;106:110171.

92 Kilbourne AM, Beck K, Spaeth-Rublee B, et al. Measuring and improving the quality of mental health care: a global perspective. World Psychiatry 2018;17:30-8.

93 OECD. Making mental health count. focus on health. Paris: OECD, 2014.

94 WHO. Integrating mental health into primary care: a global perspective. Geneva: World Health Organization, 2008.

95 Patel V, Saxena S, Lund C, et al. The Lancet Commission on global mental health and sustainable development. The Lancet 2018;392:1553-98.

96 Knaak S, Patten S, Ungar T. Mental illness stigma as a quality-ofcare problem. Lancet Psychiatry 2015;2:863-4.

97 Leslie HH, Hirschhorn LR, Marchant T, et al. Health systems thinking: a new generation of research to improve healthcare quality. PLoS Med 2018;15:e1002682-e82.

98 Sawyer SM, Azzopardi PS, Wickremarathne D, et al. The age of adolescence. Lancet Child Adolesc Health 2018;2:223-8.

99 Olfson M, He J-P, Merikangas KR. Psychotropic medication treatment of adolescents: results from the National comorbidity Survey-Adolescent supplement. J Am Acad Child Adolesc Psychiatry 2013;52:378-88.

100 Tsai C-Y, Yang H-C, Islam M, et al. Psychotropic medications prescribing trends in adolescents: a nationwide population-based study in Taiwan. Int J Qual Health Care 2017;29:861-6.

101 L B, D C, M D. Principles in using psychotropic medication in children and adolescents. in: in Rey JM MA, ed. IACAPAP e-Textbook of child and adolescent mental health. Geneva: international association for child and adolescent psychiatry and allied professions 2019;2019.

102 Langarizadeh M, Tabatabaei MS, Tavakol K, et al. Telemental health care, an effective alternative to conventional mental care: a systematic review. Acta Inform Med 2017;25:240-6.

103 Galagali PM, Brooks MJ. Psychological care in low-resource settings for adolescents. Clin Child Psychol Psychiatry 2020;25:698-711.

104 Wood SM, White K, Peebles R, et al. Outcomes of a rapid adolescent telehealth scale-up during the COVID-19 pandemic. $J$ Adolesc Health 2020;67:172-8.

105 Skinner H, Biscope S, Poland B, et al. How adolescents use technology for health information: implications for health professionals from focus group studies. J Med Internet Res 2003;5:e32.

106 Garrett CC, Hocking J, Chen MY, et al. Young people's views on the potential use of telemedicine consultations for sexual health: results of a national survey. BMC Infect Dis 2011:11:285.

107 McPherson A. Adolescents in primary care. BMJ 2005;330:465-7.

108 Svirydzenka N, Ronzoni P, Dogra N. Meaning and barriers to quality care service provision in child and adolescent mental health services: qualitative study of stakeholder perspectives. BMC Health Serv Res 2017;17:151.

109 WHO, OECD, WB. Delivering quality health services: a global imperative for universal health coverage. Geneva: World Health Organization, 2018.

110 Sawyer SM, Ambresin A-E, Bennett KE, et al. A measurement framework for quality health care for adolescents in hospital. J Adolesc Health 2014:55:484-90.

111 NHS. You're welcome quality criteria: making health services young people friendly. London: NHS, 2007. 